\title{
Regression Modeling for Spur Gear Condition Monitoring Through Oil Film Thickness Based on Acoustic Emission Signal
}

\author{
Yasir Hassan Ali ${ }^{1}$, Roslan Abd Rahman ${ }^{2} \&$ Raja Ishak Raja Hamzah ${ }^{3}$ \\ ${ }^{1}$ Department of Applied Mechanics and Design, Faculty of Mechanical Engineering, University Technology \\ Malaysia, Johor, Malaysia \\ Correspondence: Raja Ishak Raja Hamzah, Department of Applied Mechanics and Design, Faculty of \\ Mechanical Engineering, University Technology Malaysia, 81310 UTM Skudai, Johor Bahru, Johor, Malaysia. \\ Tel: 60-197-511-951. E-mail: rishak@fkm.utm.my/yha2006@gmail.com/rosln@fkm.utm.my
}

Received: January 28, 2015

Accepted: February 12, 2015

Online Published: July 6, 2015

doi:10.5539/mas.v9n8p21

URL: http://dx.doi.org/10.5539/mas.v9n8p21

\begin{abstract}
The main purpose of a gear lubricant is to provide adequate oil film thickness to reduce and prevent gear tooth surface failures .Until now, there is no study in the literature related to the estimation of oil film thickness through Acoustic emission signals. In this study, for spur gear condition monitoring a new approach based on mathematical model was presented for oil film regimes detection.

This study focuse on the ability of regression model to find whether the gearbox is running in elastohydrodynamic, mixed wear or severe wear lubrication regime. Then, predaction the accuracy of the model is measured by examining the error that been produced by using Mean Squared Error and Mean Absolute Error. In this paper a mathematical model for time-series prediction was considered and the results shows the ability of the regression model to predict oil film regime.
\end{abstract}

Keywords: regression, acoustic emission, condition monitoring, oil film thickness, spur geaer

\section{Introduction}

A gear system is not only a crucial component of a machine, but also represents an essential functional module. Any unpredictable failures in a gear system often result in circumstances that are dangerous and can have severe financial consequences (Ali, Rahman et al. 2014, Ali 2014). Thus gears need to be inspected periodically for sound, vibration and development of cracks (if any), teeth, and bearings failures. Gear failures are generally due to bending, fatigue, contact fatigue, wear and scuffing. These faults in gear can be detected by monitoring vibration, torque, temperature, acoustic and lubrication film thickness continuously or online. Due to the damage on teeth surface vibration, torque, temperature, acoustic emission of gear shaft increases and condition of oil film thickness change to mixed wear, severe wear or elastohydrodynamic (EH) (Sreepradha, Kumari et al. 2014).

Condition monitoring of machines is gaining importance in industry because of the need to increase reliability and to decrease possible loss of production. To achieve this, it is necessary to establish a maintenance monitoring program to regularly assess the condition of a machine. There are a number of different methods that can be employed for machine condition monitoring to support maintenance decisions. The use of oil analysis, vibration and acoustic emission (AE) signals is quite common in the field of condition monitoring of rotating machinery (Peng and Kessissoglou 2003; Samanta, Al-Balushi et al. 2003).

Estimation or measurement of lubricating oil film thickness has been carried out by many researchers to predict healthy or unhealthy condition of the machine. Major purpose of a gear lubricant is to provide adequate oil film thickness to reduce and prevent gear tooth surface wear, to predict and overcome wear related damage progression in gear transmission systems. Various condition monitoring techniques have been developed in the past, which includes vibration, acoustic emission, oil/wear and sound analysis (Sung, Tai et al. 2000; Amarnath, Sujatha et al. 2009). The experimental results from the tests clearly show a direct correlation between AE RMS and the specific film thickness $(\lambda)$ it was reported that the measured AE RMS was very sensitive to changes in specific film thickness (Hamzah, Al-Balushi et al. 2008; Raja Hamzah and Mba 2009; Hamel, Addali et al. 2014).

Mathematical modeling and statistical analysis is used here to characterize the causes of the gear failure in terms 
of classifying oil film thickness with acoustic emission signal. Regression model was used to estimate/classify oil film thickness for condition monitoring of satisfactory gear operation and thereby resolving the faults diagnosing issues. Thus, to carry out the failure analysis of gear, AE RMS are used to predict the oil film thickness. The Regression modeling is one of the statistical approaches to derive the mathematical model for machine condition monitoring (ZHANG and NIE 2009). The regression based model is considered as the simplest approach to build a normal behavior model and may be used for monitoring (Schlechtingen and Ferreira Santos 2011).Time series regression models attempt to predict a future response based on the response history. In recent times there have been widespread interests in the use of multiple models for pattern classification and regression in statistics and neural network community (Subasi 2007).

Classification program was designed and used to classify the oil film thickness to Hydrodynamic lubrication (HL), Elastohydrodynamic lubrication (EHL) and Boundary lubrication (BL) based on the specific film thickness magnitude.

In this paper, we try to predict specific film thickness through AE signal because AE technique is a successful method in machinery condition monitoring and fault diagnosis due to its high sensitivity on locating micro cracks in high frequency domain. Acoustic emission waves are sent from an emission source and transferred to the surface by the transmission medium. The low displacement or high frequency mechanical waves can be picked up as electronic signals. The signal strength can be increased by using a pre-amplifier before the data are interpreted by the AE equipment (Ali, Rahman et al. 2014; Ali 2014). The data used in this research were taken from earlier research (Hamzah, Al-Balushi et al. 2008; Raja Hamzah and Mba 2009).

\section{Methodology}

\subsection{Experimental Setup and Data Acquisition System}

Figure1 illustrates the test rig used for the experiments which is a standard back-to-back gearbox with oil-bath lubrication. A summary is listed in table 1, which describes the test gear description. Using Mobil MOBILGEAR 636 as the lubricant, the tests were conducted under high pressure. Table 2 summarise the selection of the lubricant to decrease the frequency of natural pitting and wear, and the lubricant characteristics.

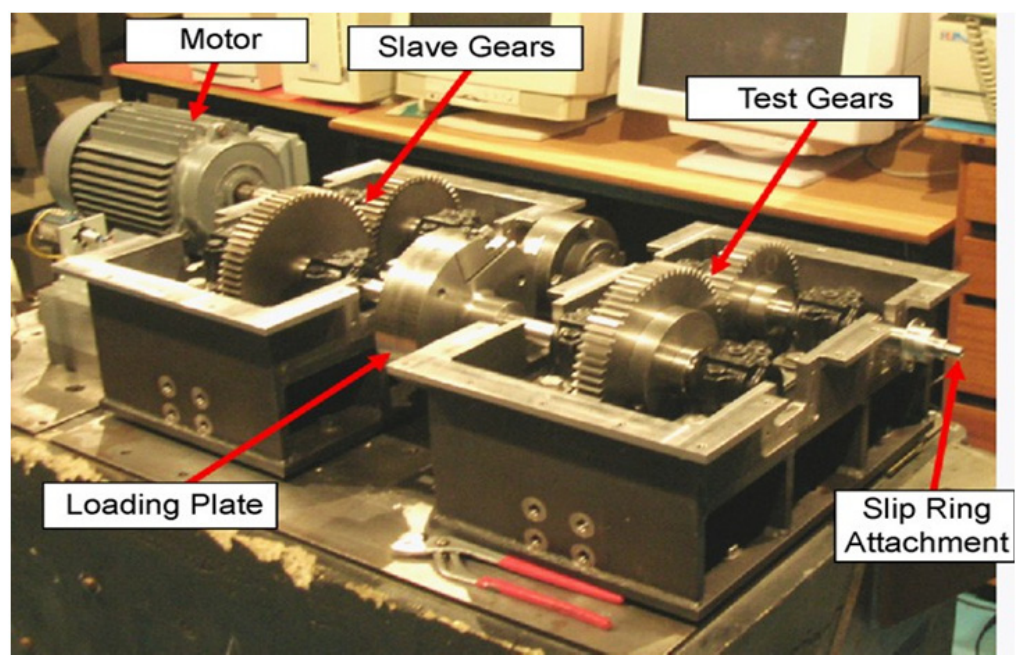

Figure 1. Back-to-back test gearbox arrangement. (Raja Hamzah and Mba 2009)

Table 1. Test gears specifications

\begin{tabular}{ll}
\hline Number of teeth, pinion: gear & $49: 65$ \\
\hline Base diameter, pinion: gear $(\mathrm{mm})$ & $138.13: 183.24$ \\
Pitch diameter, pinion: gear (mm) & $147.00: 195.00$ \\
Tip diameter, pinion: gear (mm) & $153.00: 201.00$ \\
Contact ratio & 1.33 \\
Module (mm) & 3.00 \\
Addendum modification coefficient & 0 \\
Surface roughness, Ra (mm) & 2.00 \\
Face width (mm) & 30.00 \\
\hline
\end{tabular}


Pressure angle $\left({ }^{0}\right) \quad 2.00$

Modulus of elasticity (GPa) $\quad 228.00$

Table 2. Lubricant properties

\begin{tabular}{ll}
\hline Viscosity & \\
$40{ }^{0} \mathrm{C}(\mathrm{cSt})$ & 680.0 \\
$100{ }^{\circ} \mathrm{C}(\mathrm{cSt})$ & 39.2 \\
\hline Density at $15.6{ }^{0} \mathrm{C}(\mathrm{kg} / \mathrm{l})$ & 0.91 \\
Viscosity index & 90.0 \\
Pour point $\left({ }^{0} \mathrm{C}\right)$ & -9.0 \\
Flash point $\left({ }^{0} \mathrm{C}\right)$ & 285.0 \\
Pressure viscosity coefficient, $\alpha(\mathrm{mm} 2 / \mathrm{N})$ & $2.2 \times 10-8$ \\
\hline
\end{tabular}

The set-up included a Model WD wideband AE sensor capable of picking up relatively flat responses in the range $100 \mathrm{kHz}-1 \mathrm{MHz}$ (Physical Acoustic Corp.).To a commercial data acquisition system, the silver contact slip rings transmitted the $\mathrm{AE}$ signals from the rotating test pinion to a commercial data acquisition system (figure1).At 20 and $40 \mathrm{~dB}$, sensor signals were preamplified throughout the testing. With an analogue-to-digital converter (ADC), software interfaced captured the gearbox test-rig was set to constantly record AE RMS signals. The torque loading parameters were 60,120 , and $250 \mathrm{Nm}$ and the gearbox was run at $700 \mathrm{rpm}$. At this speed, one complete revolution of the pinion was signified by the selected speed approximately. Using the accumulated squared ADC values, the RMS could then be calculated. An anti-aliasing filter was used before signal sampling at the ADC. The AE waveform sampling rate was $10 \mathrm{MHz}$ and the digital filtering range was 100-1200 $\mathrm{kHz}$ (Hamzah, Al-Balushi et al. 2008, Raja Hamzah and Mba 2009).

\subsection{Mathematical Principles}

Oil lubrication prevents the gear teeth coming into direct contact and decreases friction, vibration, heat build-up and corrosion. (Hamel, Addali et al. 2014). $\lambda$ ratio is defined as the oil film thickness (h) divided by the composite surface roughness $\left(\sigma_{\mathrm{rms}}\right)$.

$$
h=\frac{k\left(\eta_{o} u\right)^{0.7} R^{0.43}}{w^{0.13}} u m
$$

Where $k=1.6 \alpha^{0.6} \mathrm{E}^{0.03}$

$$
\lambda=\frac{h}{\sigma_{r m s}}
$$

$\eta \mathrm{o}=$ Dynamic viscosity in Pa.s

$\mu=$ Entraining velocity in $\mathrm{m} / \mathrm{s}$

$\mathrm{R}=$ Equivalent radius in $\mathrm{m}$

$\mathrm{w}=$ Load applied along the line of contact in $\mathrm{N} / \mathrm{m}$

$\alpha=$ Pressure viscosity coefficient in $\mathrm{mm} 2 / \mathrm{N}$

$\mathrm{E}=$ Modulus of elasticity of the gear in $\mathrm{Pa}$

The film thickness is indicative of the lubrication regime between two rough surfaces. The film is affected by high pressure contact and sliding, which causes heat generation and changes in physical properties. Typical operating conditions cause the lubricant to become thin, reducing protection against rubbing at the surfaces and resulting in lubricant failure. The characteristics of the lubricant are therefore crucial to maintain the minimum film thickness under specific operating conditions and this would require a sufficiently large $\lambda$ ratio (Sreepradha, Kumari et al. 2014).

Three different lubrication regimes can be differentiated depending on the lubricant film thickness which are Hydrodynamic lubrication (HL), Elastohydrodynamic lubrication (EHL) and Boundary lubrication (BL). Mixed lubrication is an intermediate regime among elastohydrodynamic and boundary lubrication. Full hydrodynamic lubrication would normally occur at $\lambda>10$. This condition would create minimal friction and wear with no direct surface interaction. Pressure transmitted through the lubricant would characterize the only likely fatigue mechanism. Gears generally operate with the elastohydrodynamic regime $(2<\lambda<10)$ and at a lower film 
thickness ratio there is possibility of interaction on the moving surfaces from asperities in the lubricant producing wear. The effect of thermal and pressure conditions on the surfaces can effect in larger asperities in the lubricant and lead to film failure, which bases severe wear, such as scuffing. Boundary and dry lubrication would classically arise at $\lambda<2$. Figure 2 shows the 'Stribeck Curve' illustrating the $\lambda$ values in several lubrication regimes (Hamel, Addali et al. 2014).

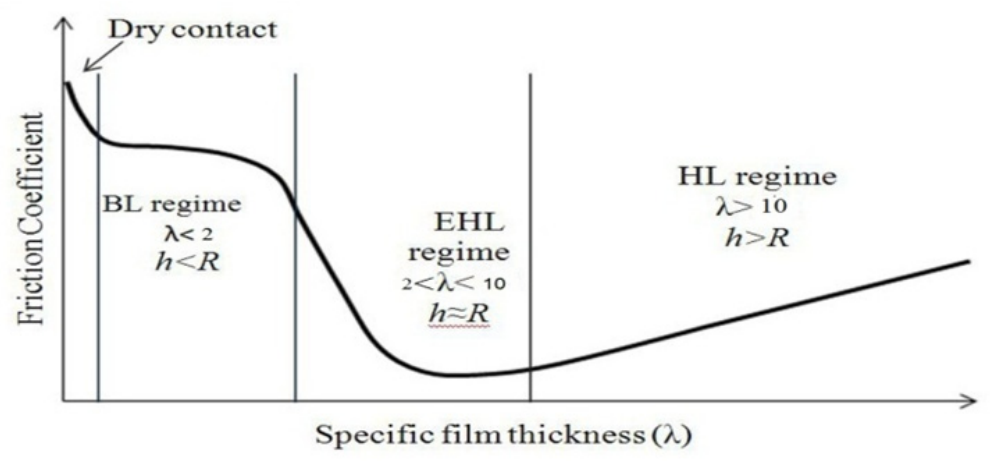

Figure 2. The Stribeck curve and specific film thickness ( $\lambda$ ) (Hamel, Addali et al. 2014)

\subsection{Statistical Error}

The performance of the mathematical models is evaluated by statistical error analyses which identify the most suitable model. Two types of error analysis were used to evaluate the models.

\subsubsection{Mean Squared Error (MSE)}

An error is the difference between the predicted and actual. The MSE finds the average of the squares of the predicted errors, which corresponds to the risk factor the model represented, because of quadratic or squarederror loss. The cause of the difference is either due to the random approach or certain information has not been processed during the prediction, which would have produced a more accurate estimate. If $Y$ i is a vector of $\mathrm{n}$ predictions, and $Y i$ is the vector of the actual values, then the (estimated) MSE of the predictor is:

$$
M S E=\frac{1}{n} \sum_{i=1}^{n}\left(\dot{Y}_{i}-Y_{i}\right)^{2}
$$

\subsubsection{Mean absolute error (MAE)}

The MAE is a quantity is commonly used to predict error when analysing time series, which comparing the closeness of predicted and actual values given by the following equation:

$$
M A E=\frac{1}{n} \sum_{i=1}^{n}\left|\dot{Y}_{i}-Y_{i}\right|
$$

\subsection{Prediction by Regression Model}

Regression analysis is a statistical tool for the investigation of relationships between variables.

$$
Y=\alpha+\beta X+\mu
$$

Regression models quantitatively describe the variability among the observations by partitioning an observation into two parts (Li, Wunsch et al. 2001). The first part of this decomposition is the predicted portion having the characteristic that can be desecribed to all the observations considered as a group in a parametric framework. The remaining portion, called the residual, is the difference between the observed and the predicted values and must be ascribed to unknown sources. In order to develop relationship between Lambda and RMS, set of equations are be developed for speed $\mathrm{S}$ such that a total of 3 set of equations is established such as:

Generalized form of equation for S speed:

$$
\lambda_{S n L n}=\alpha+\beta(R M S)_{n}+\mu
$$

Where $\lambda$ stands for specific film thickness of oil (Lambda)

$\mathrm{S}$ is speed of machine 
$\mathrm{L}$ is load condition of $\mathrm{S}$ speed

Where $\mathrm{n}=1,2,3 \ldots \mathrm{n}$

$\alpha$ is the intercept and is taken as constant

$\beta$ is the slope coefficient of RMS

RMS is root mean squaredof acoustic emission signal.

And $\mu$ is the stochastic error term which absorb the effect of all those variables which are not included in the equation or omitted and which can affect the relationship between $\lambda$ and RMS

A machine with speed $\mathrm{S}$ will have the following set of equations:

$$
\begin{aligned}
& \lambda_{S L 1}=\alpha+\beta(R M S)_{n}+\mu \\
& \lambda_{S L 2}=\alpha+\beta(R M S)_{n}+\mu \\
& \lambda_{S L 3}=\alpha+\beta(R M S)_{n}+\mu
\end{aligned}
$$

First, the Regression model was built by using the acoustic emission signals and specific film thickness, where the acoustic emission signals used to build the regression model is shown in Figure 3.

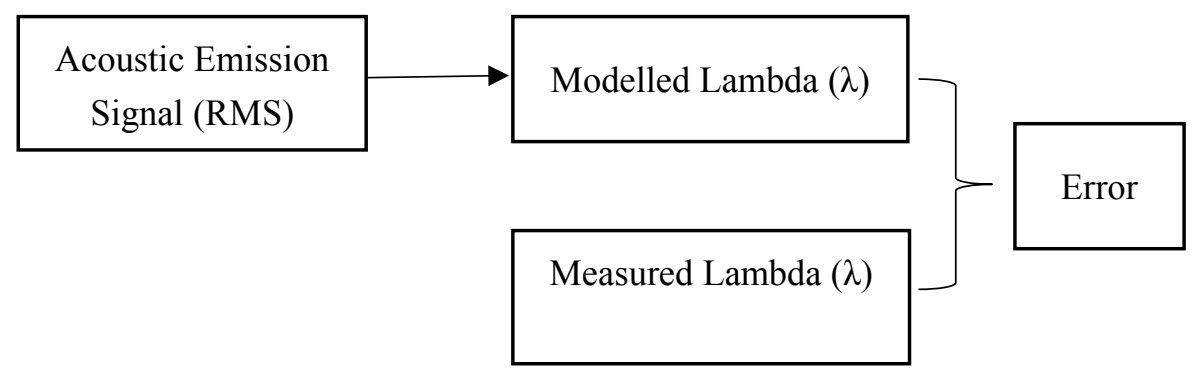

Figure 3. Regression model schematic (Schlechtingen and Ferreira Santos 2011)

\section{Result and Discussion}

The whole model test for speed and load conditions and all the result are listed in this section.

Table 3. Estimated elasticities for a machine with speed S (700rpm) and load condition L1 (60Nm) using the Least Squaredapproach

\begin{tabular}{cccc}
\hline Variable & Coefficient & Std. Error & Prob. \\
\hline Constant & 11,4 & 0.0844 & 0.0000 \\
RMS & -112.106 & 1.208 & 0.0000 \\
\hline
\end{tabular}

R-squared $=81.2 \%$; Adjusted R-squared $=81.2 \%$.

Table 3 shows the result for a machine having speed S (700rpm) and a load condition of L1 (60Nm) depicts a negative relationship between Lambda and RMS. The coefficient of RMS indicates that in every second an increase in the Lambda will cause a decrease in the acoustic emission signal (RMS). The overall model is statistically significant and robust as revealed by the result from the table. The value of R-Squaredand Adjusted R-Squaredsuggests that the model is best fit showing that overall $81.2 \%$ of variation in the RMS is caused by Lambda.

Table 4. Estimated elasticity's for a machine with speed S (700rpm) and load condition L2 (120Nm) using the Least Squaredapproach

\begin{tabular}{cccc}
\hline Variable & Coefficient & Std. Error & Prob. \\
\hline Constant & 12.2500 & 0.0915 & 0.0000 \\
RMS & -85.4427 & 0.8630 & 0.0000 \\
\hline
\end{tabular}

R-squared= 83.1\%; Adjusted R-squared== 83.1\%. 
Table 4 shows an inverse relationship between thickness of oil film (Lambda) and acoustic emission signal (RMS). It reveals that when a machine shift to L2 load condition while with the same speed S1 still there is a negative association between Lambda and RMS.Thus with the increase in the thickness of oil film the acoustic emission signal tends to get weakened or reduced. The equation/ model developed was found to be robust where, the R-squaredand Adjusted R-squaredvalues shows a strong relationship between lambda and RMS as $83.1 \%$ of variation in the RMS occurs due to the changes in lambda.

Table 5. Estimated elasticity's for a machine with speed S (700 rpm) and load condition L3 (250Nm) using the Least Squaredapproach

\begin{tabular}{cccc}
\hline Variable & Coefficient & Std. Error & Prob. \\
\hline Constant & 17.8429 & 0.1500 & 0.0000 \\
RMS & -63.3236 & 0.6621 & 0.0000
\end{tabular}

R-squared= 82.1\%; Adjusted R-squared=82.1\%.

The thickness of oil film (lambda) inversely affects the acoustic emissionl signal (RMS) when the machine with S speed $(700 \mathrm{rpm})$ has a load condition of L3 $(250 \mathrm{Nm})$. The R-squaredand Adjusted R-squaredvalues shows a strong relationship between lambda and RMS as $82.1 \%$ of variation in the RMS occurs due the changes in lambda. As shown in the tables above, the regression model established from the acoustic emission data collected through spur gear is significant in predicting oil film thickness. The parameter estimated and the R2 values in tables tell that RMS is a significant factors in explaining Lambda.

The prediction error for the full regression model for the speed and three load condition is illustrated in figure 4 which represents the output error for the regression models. The output error denotes the differences between the target (lambda) and the modelled output from the regression model.

Output error $=$ target - modelled output.

From this figure it can be seen that apart from the few outliers $(\times)$, the regression model is capable of predicting the specific film thickness in the range of \pm 4 . The remaining outliers are caused by extreme transient situations during the experiment, the oil mist generated as a result of the churning of the oil formed a 'frozen mist' as the oil temperature approached $0^{\circ} \mathrm{C}$. This frozen oil mist was thrown into the gear mesh by the rotating wheel resulting in the generation of $\mathrm{AE}$ activity. In this sense normal operational temperature profiles are modeled well. The problem can be either overcome by implementation of separate models for transient situations or by simple filtering. Filtering of non-operational periods is possible, since determination of the component condition based on online data is most reasonable if the gear is operating. By the use of the value of RMS and lambda in EHL regime we can get better prediction and the prediction error will be lower. 


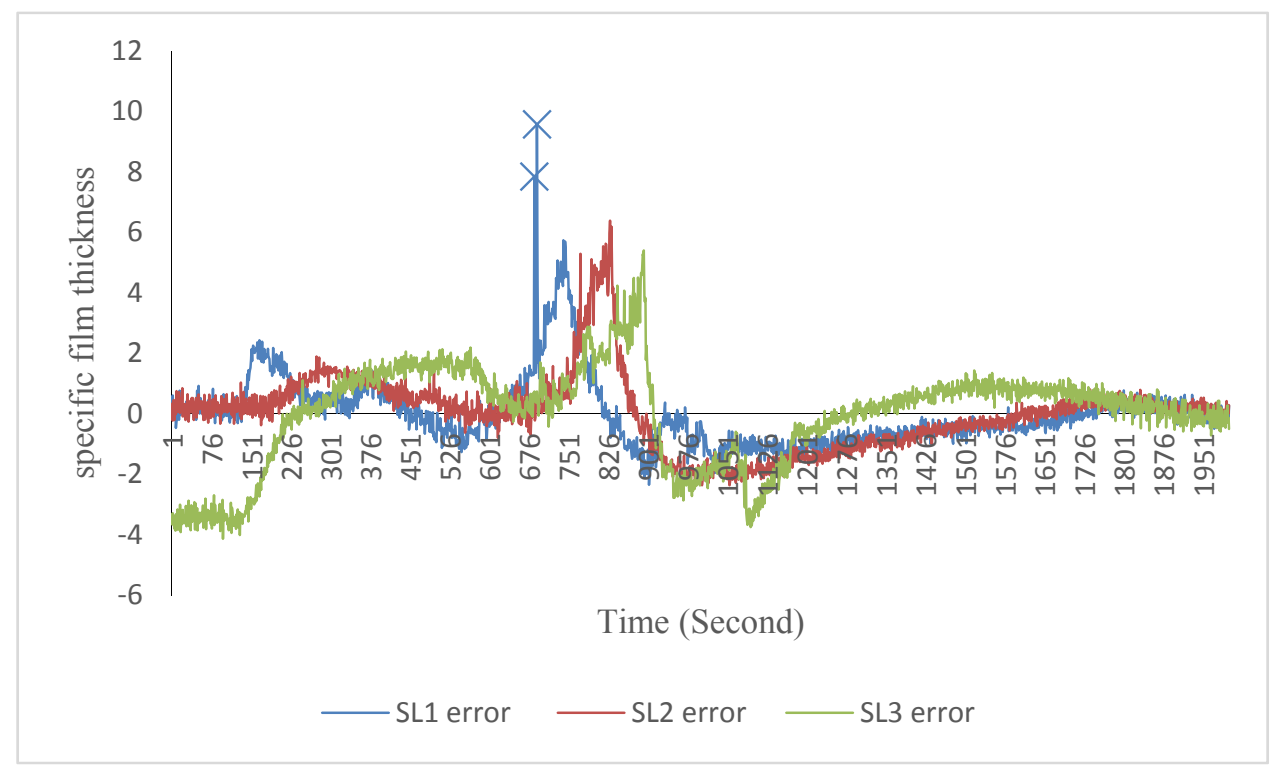

Figure 4. Regression model error

This work is important because it shows that the regression model can be used for predicting the oil film thickness through acoustic emission signal. For that purpose, acoustic emission signal (RMS) used to predict the oil film thickness in spur gear and these data are used to build the regression model. Two statistical errors have been used to assess the performance of the model. The result in Table 6 indicates that the performance of the model for the three load and speed conditions. The model represents good results for the first load and speed conditions (SL1) where the MSE and MAE values are small compared to the other conditions. At the same time, the value of the statistical errors measurement for load and speed conditions (SL3) is higher than the other conditions because the performance of the model for (SL3) is less than the others.

Table 6. Regression model performance and classification success results

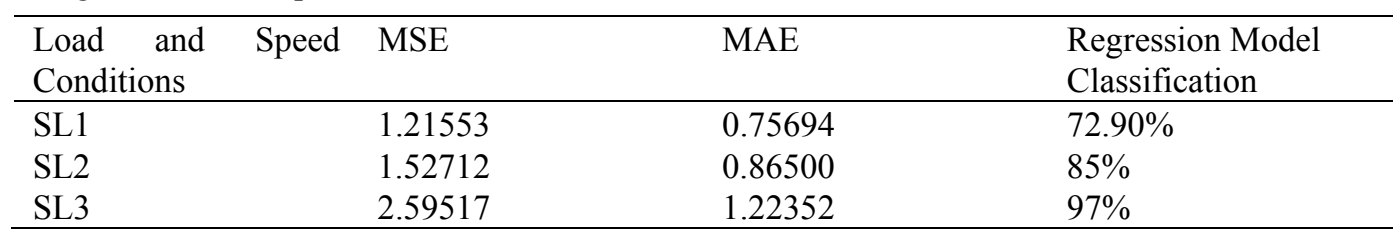

Classification program is designed and used to classify the oil film regime in gear, the program used with estimated data. When the regression models were tested with acoustic emission data sets and oil film thickness, the models yielded a predicted oil film thickness. This value was used in the program and the results is shown in Table 6. The result of this program demonstrates that the regression model have the ability to give a good performances of classification accuracy.

\section{Conclusion}

This study proposes a regression model to improve the accuracy of oil film thickness prediction for spur gear based on acoustic emission signal. The results showed that the regression models were can be used in prediction and this suggested technique attained $85 \%$ success in prediction.

This study shows the overall model developed and is found to be statistically significant. The statistical errors measurement which have been used to assess the performance of the models indicates that the performance of the regression model is good. Moreover the R-squared and Adjusted R-squared values shows a strong relationship between Lambda and RMS as over $80 \%$ of variation in the RMS occurs due the changes in Lambda. For this reasons the proposed method can be used to monitor the spur gear. 


\section{References}

Ali, Y. H., Rahman, R. A., \& Hamzah, R. I. R. (2014). Acoustic Emission Signal Analysis and Artificial Intelligence Techniques in Machine Condition Monitoring and Fault Diagnosis: A Review. Jurnal Teknologi, 69(2). http://dx.doi.org/10.11113/jt.v69.3121

Ali, Y. H. M. H. O., Rahman, R. A., \& Hamzah, R. I. R. (2014). Acoustic emission technique in condition monitoring and fault diagnosis of gears and bearings. International Journal of Academic Research Part A $6(5), 6$.

Amarnath, M., Sujatha, C., \& Swarnamani, S. (2009). Experimental studies on the effects of reduction in gear tooth stiffness and lubricant film thickness in a spur geared system. Tribology international, 42(2), 340-352. http://dx.doi.org/10.1016/j.triboint.2008.07.008

Hamel, M., Addali, A., \& Mba, D. (2014). Investigation of the influence of oil film thickness on helical gear defect detection using Acoustic Emission. Applied Acoustics, 79, 42-46. http://dx.doi.org/10.1016/j.apacoust.2013.12.005

Hamel, M., Addali, A., \& Mba, D. (2014). Monitoring oil film regimes with acoustic emission. Proceedings of the Institution of Mechanical Engineers, Part J: Journal of Engineering Tribology, 228(2), 223-231. http://dx.doi.org/10.1177/1350650113503631

Hamzah, R. R., Al-Balushi, K. R., \& Mba, D. (2008). Observations of acoustic emission under conditions of varying specific film thickness for meshing spur and helical gears. Journal of Tribology, 130(2), 021506. http://dx.doi.org/10.1115/1.2908915

Li, S., Wunsch, D. C., O'Hair, E., \& Giesselmann, M. G. (2001). Comparative analysis of regression and artificial neural network models for wind turbine power curve estimation. Journal of Solar Energy Engineering 123(4), 327-332. http://dx.doi.org/10.1115/1.1413216

Peng, Z., \& Kessissoglou, N. (2003). An integrated approach to fault diagnosis of machinery using wear debris and vibration analysis. Wear, 255(7), 1221-1232. http://dx.doi.org/10.1016/S0043-1648(03)00098-X

Raja Hamzah, R., \& Mba, D. (2009). The influence of operating condition on acoustic emission (AE) generation during meshing of helical and spur gear. Tribology International, 42(1), 3-14. http://dx.doi.org/10.1016/j.triboint.2008.06.003

Samanta, B., Al-Balushi, K., \& Al-Araimi, S. (2003). Artificial neural networks and support vector machines with genetic algorithm for bearing fault detection. Engineering Applications of Artificial Intelligence, 16(7), 657-665. http://dx.doi.org/10.1016/j.engappai.2003.09.006

Schlechtingen, M., \& Santos, I. F. (2011). Comparative analysis of neural network and regression based condition monitoring approaches for wind turbine fault detection. Mechanical Systems and Signal Processing, 25(5), 1849-1875. http://dx.doi.org/10.1016/j.ymssp.2010.12.007

Sreepradha, C., Kumari, A. K., Perumal, A. E., Panda, R. C., Harshabardhan, K., \& Aribalagan, M. (2014). Neural network model for condition monitoring of wear and film thickness in a gearbox. Neural Computing and Applications, 24(7-8), 1943-1952. http://dx.doi.org/10.1007/s00521-013-1427-6

Subasi, A. (2007). EEG signal classification using wavelet feature extraction and a mixture of expert model. Expert Systems with Applications, 32(4), 1084-1093. http://dx.doi.org/10.1016/j.eswa.2006.02.005

Sung, C., Tai, H., \& Chen, C. (2000). Locating defects of a gear system by the technique of wavelet transform. Mechanism and Machine Theory, 35(8), 1169-1182. http://dx.doi.org/10.1016/S0094-114X(99)00045-2

Zhang, J., \& Nie, H. (2009). Experimental study and logistic regression modeling for machine condition monitoring through microcontroller-based data acquisition system. Journal of Advanced Manufacturing Systems, 8(2), 177-192. http://dx.doi.org/10.1142/S0219686709001742

\section{Copyrights}

Copyright for this article is retained by the author(s), with first publication rights granted to the journal.

This is an open-access article distributed under the terms and conditions of the Creative Commons Attribution license (http://creativecommons.org/licenses/by/3.0/). 